\title{
Distant mood monitoring for depressive and bipolar disorders: a systematic review
}

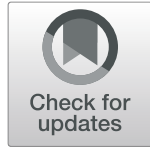

\author{
A. S. J. van der Watt ${ }^{*} \mathbb{D}$, W. Odendaal ${ }^{1,2}$, K. Louw $^{1}$ and S. Seedat ${ }^{1}$
}

\begin{abstract}
Background: Broadening our knowledge of the longitudinal course of mood symptoms is cardinal to providing effective long-term treatments. Research indicates that patients with mental illness are willing to engage in the use of telemonitoring and mobile technology to assess and monitor their mood states. However, without the provision of distant support, adverse outcomes and events may be difficult to prevent and manage through self-monitoring. Understanding patient perspectives is important to achieving the best balance of self-monitoring, patient empowerment, and distant supporter involvement.

Methods: This systematic review synthesises quantitative and qualitative evidence of the effectiveness and feasibility of daily/weekly/monthly remote mood monitoring that includes distant support in participants with mood disorders. Inclusion criteria comprised mood monitoring of mood disorder patients as main intervention, study design, method of monitoring, and presence of psychotherapy and psychoeducation. Effectiveness was defined by the change in depression and/or mania scores. Feasibility was determined on participant feedback and completion/attrition rates. Studies were assessed for quality using the Mixed Methods Appraisal Tool version 2018.

Results: Nine studies of acceptable quality met the inclusion criteria. Distant mood monitoring was effective in improving depression scores but not mania scores. Feasibility, as measured through compliance and completion rates and participant feedback, varied.

Conclusion: Distant mood monitoring with support may be a useful, acceptable, and feasible intervention for diverse groups of patients in terms of age and ethnicity. Further, it may be effective in improving symptoms of depression, increasing treatment adherence, and facilitating the prevention and management of adverse outcomes. As a task-shifting intervention, distant mood monitoring may help to alleviate the burden on mental health providers in developing countries.
\end{abstract}

Keywords: Affective disorder, Distant, Intervention, LMIC, Mood disorder, Monitoring, Task-shifting, South Africa

\section{Background}

Broadening our knowledge of the longitudinal course of mood symptoms is cardinal to understanding bipolar and unipolar depression, and other affective disorders (hereafter referred to as mood disorders) and providing long-term effective treatments. This includes patterns of

\footnotetext{
* Correspondence: bertevdwatt@sun.ac.za

${ }^{1}$ Department of Psychiatry, Stellenbosch University, Tygerberg, South Africa Full list of author information is available at the end of the article
}

chronicity, episodicity, relapse, and recurrence $[1,2]$, especially for bipolar disorder [3]. Such knowledge underlines the investigation of pathophysiological mechanisms, assists in guiding and optimising treatment (e.g. dose, duration [4]), and informs the development of novel and more effective treatments [5].

Research indicates that patients with psychiatric disorders readily engage in the use of telemonitoring [6] and mobile technology $[7,8]$ as forms of mood assessment, monitoring, and treatment; allowing for more regular

(C) The Author(s). 2020 Open Access This article is licensed under a Creative Commons Attribution 4.0 International License, which permits use, sharing, adaptation, distribution and reproduction in any medium or format, as long as you give appropriate credit to the original author(s) and the source, provide a link to the Creative Commons licence, and indicate if changes were made. The images or other third party material in this article are included in the article's Creative Commons licence, unless indicated otherwise in a credit line to the material. If material is not included in the article's Creative Commons licence and your intended use is not permitted by statutory regulation or exceeds the permitted use, you will need to obtain permission directly from the copyright holder. To view a copy of this licence, visit http://creativecommons.org/licenses/by/4.0/ The Creative Commons Public Domain Dedication waiver (http://creativecommons.org/publicdomain/zero/1.0/) applies to the data made available in this article, unless otherwise stated in a credit line to the data. 
data collection on mood trajectories. A systematic review of the validity of electronic self-monitoring of mood using information technology (IT) platforms in adults with bipolar disorder found evidence of their validity when compared to clinical rating scales for depression [9].

Both weekly telemonitoring and text messaging allow for improved access to professional care in patients with bipolar disorder $[6,10,11]$ and may facilitate symptom improvement. For example, patients with bipolar disorder endorsed lower levels of illness experienced during facilitated integrated mood management [8]. Telemonitoring and text messaging to monitor patients' mood fluctuations, though not cost-free, is far less expensive than traditional clinical interviews $[8,11]$. Lastly, these interventions may assist in increasing treatment adherence which is of benefit as non-adherence is a major and costly concern in the treatment of mood disorders [11].

Whilst electronic self-monitoring and intervention programmes may promote patient self-management and empowerment, keeping some form of interaction with trained supporters (such as clinicians, counsellors, and researchers) is positively valued by patients and allows for a more personalised approach that improves efficiency $[1,12,13]$. Additionally, the prevention and management of adverse outcomes and events may be hampered without the proper involvement of clinicians [14] or other trained supporters. Further, involvement of trained supporters may indirectly increase the effectiveness of the intervention through the quasi-therapeutic experience [15]. Optimising treatment and minimising adverse events in distant mood monitoring programs requires an understanding of patients' perspectives so that the best balance between self-monitoring, patient empowerment, and distant supporter involvement can be achieved [16]. Further, the COVID-19 pandemic has highlighted the need for a better understanding of telepsychiatry and distant interventions, which is corroborated by the April 2019 release of the World Health Organization (WHO) guideline on digital interventions for health system strengthening [17]. There is likely to be a surge of research in this area, as reflected in the 25 effectiveness reviews on digital health published by the Cochrane Library [18] and two overviews of reviews on digital health $[19,20]$ that jointly identified 29 systematic reviews, of which 17 were non-Cochrane reviews.

This systematic review evaluates the effectiveness and feasibility of distant mood monitoring, with support, in individuals with mood disorders.

\section{Objectives}

We synthesised quantitative and qualitative evidence on the effectiveness and feasibility of daily/weekly/monthly remote mood monitoring in participants with any mood disorder (as defined above) by clinicians, lay counsellors, and researchers (hereafter referred to as distant supporters), or where regular feedback was provided by distant supporters in cases where mood states were selfassessed. Assessment of effectiveness was based on the change in depression and/or mania scores. Feasibility was determined according to completion/attrition rates and participant feedback. Studies were assessed for quality using the Mixed Methods Appraisal Tool (MMAT) version 2018 [21].

\section{Methods}

This review is registered on PROSPERO (CRD42017057227).

\section{Literature search}

The first and second authors searched the following databases to identify eligible articles:

i.) Academic search premier - EBSCOhost

ii.) PubMed - Medline

iii.) SAGE journals

iv.) Web of Science

v.) Cochrane

Additionally, the reference lists of included studies were searched to identify potentially relevant studies that may have been missed by electronic searches [22]. After the first phase of the screening process (see Fig. 1), relevant articles to which we did not have full text access were flagged. These articles were requested through an inter-library loan process at Stellenbosch University.

\section{Search strategy}

The following keywords (and MeSH terms) were used in searching for relevant literature:

Telephonic OR telephone OR mobile phone OR cellular phone OR cell phone OR smartphone OR computer OR telecommunication OR electronic OR Skype OR pen-and-paper OR paper-and-pencil OR wearables OR mood charting

AND

Psychiatric Disorder OR mental disorder

AND

Monitoring OR remote monitoring OR distant

monitoring OR no contact monitoring

AND

Clinician OR lay counsellor OR researcher OR therapist OR counsellor OR psychiatrist

\section{Eligibility criteria}

Only peer reviewed studies published in English between 01 January 2000 and 26 September 2019, were 


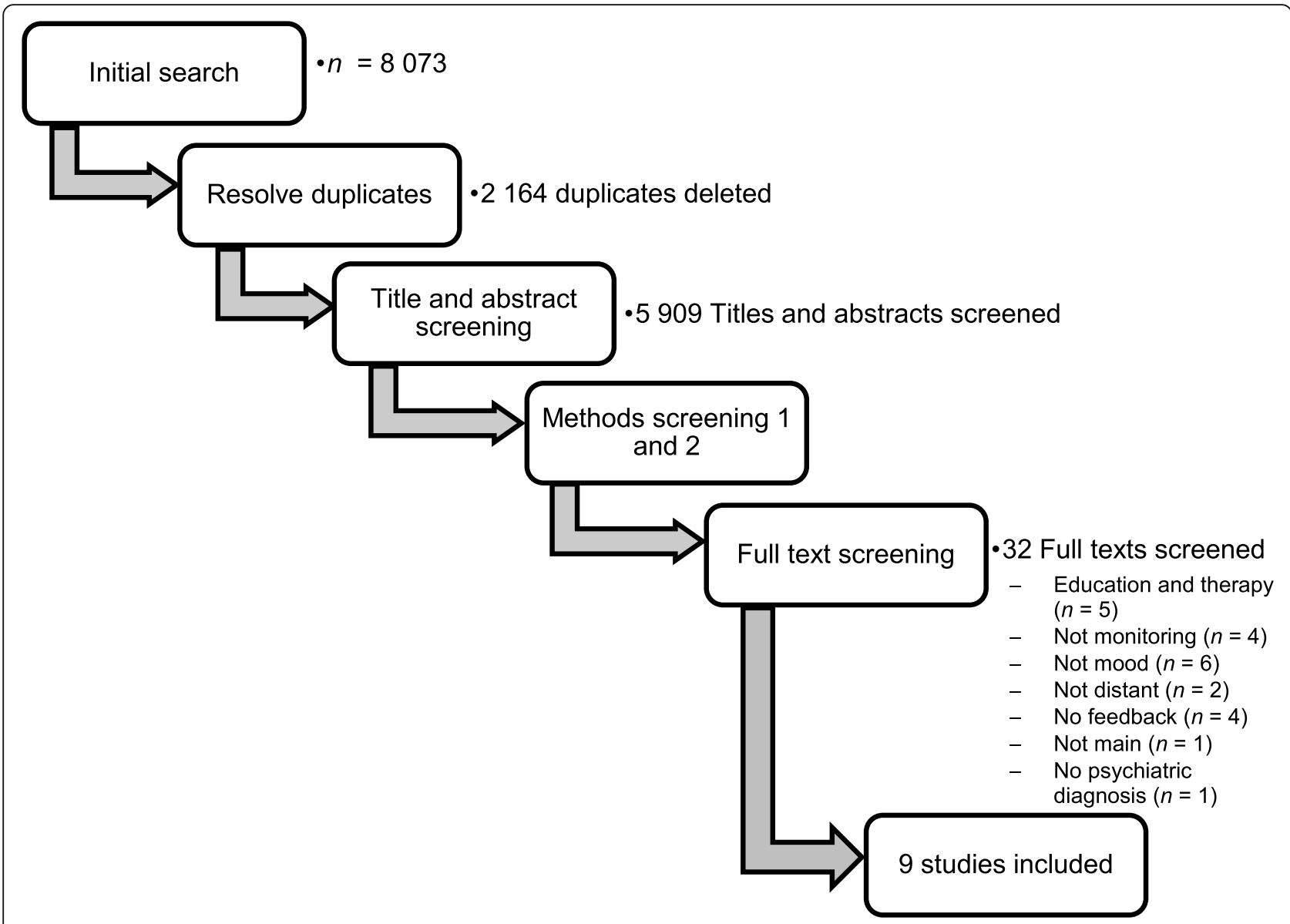

Fig. 1 Screening process

considered for the review. Inclusion criteria were not limited to study setting or location.

\section{Mood monitoring as the main intervention}

For a study to be eligible, it had to primarily focus on the effectiveness of daily/weekly/monthly distant mood monitoring of participants. Monitoring occurring at intervals longer than once a month (e.g. every 3 months) were excluded. Studies where the mood monitoring was not deemed the primary focus (or intervention), were excluded.

Participants had to have a diagnosis of a mood disorder as defined by the Diagnostic and Statistical Manual of Mental Disorders [23, 24] or the International Statistical Classification of Diseases and Related Health Problems [25].

\section{Study design}

All quantitative studies were included as well as studies that qualitatively assessed participants' perceived effectiveness, feasibility, and acceptability of distant mood monitoring offered by distant supporters. Case studies were also considered for inclusion. Systematic reviews and commentaries were excluded. Studies included in other systematic reviews that met our inclusion criteria were included, but not the systematic review itself.

\section{Method of monitoring}

Only studies in which the mood monitoring was done distantly were included, and the monitoring had to take place without any face-to-face contact (i.e. physical presence) between the study participant and the person conducting the distant mood monitoring. In the present review, monitoring refers to (i) supporters distantly monitoring participants' mood (daily, weekly, bi-weekly, or monthly) and (ii) participants monitoring their own mood (daily, weekly, bi-weekly, or monthly). With reference to the former, the focus was on studies in which mood monitoring was done distantly, without any faceto-face contact (i.e. physical presence) between the patient and the person conducting the distant mood monitoring - studies where mood monitoring took place via telephone, internet, smartphone, and/or e-mail. This monitoring had to be done by a distant supporter. With reference to the latter, self- monitoring of participants' 
own mood had to be accompanied by distant supporter feedback (daily, weekly, bi-weekly, or monthly). Studies that focused only on participants' self-monitoring of mood states in the absence of distant supporter feedback were excluded as well as studies where feedback was only computer generated without the assistance of a distant supporter.

The decision to focus on mood monitoring conducted by a distant supporter (or which at least included some feedback by a distant supporter) was based on research indicating the effectiveness of participants being listened to [26], or simply talking to a researcher interested in what they have to say [27]. As such, mood monitoring that involves contact, albeit distant, with a distant supporter may have therapeutic benefits in and of itself [28]. There is also some evidence that participants often take part in research studies, such as mood monitoring, to access the aforementioned benefits [29].

\section{Psychotherapy and psychoeducation}

Studies in which the monitoring co-occurred with psychotherapy or psychoeducation as part of the intervention, for example where telephonic mood monitoring was followed by telephonic psychotherapy, [30] were excluded. This was done to differentiate between the effectiveness of mood monitoring of itself versus psychotherapy or psychoeducation delivered distantly.

\section{Screening process}

Articles identified through the search $(N=8073)$ were exported to Rayyan [31] where the first and second authors independently assessed their eligibility using the blind function. During each screening phase (see Fig. 1), the authors indicated the main reason for exclusion using the "Reason" function in Rayyan. During each subsequent phase, the main exclusion reason applied in the previous phases could still apply (e.g. if a duplicate was missed during Phase 1, it could still be indicated as the main reason for exclusion during Phase 2 - Phase 5). The phases, with the main exclusion reasons of each, are described next.

First, duplicates $(n=2164)$ were removed. Second, titles and abstracts were screened. Main exclusion reasons included: (i) Review articles $(n=725$; including systematic reviews, literature reviews, narrative reviews, or commentary articles); (ii) Posters and presentations ( $n=$ 699; including poster/oral presentations at conferences and collections of abstracts); (iii) Animal studies $(n=44)$; (iv) Protocols $(n=274$; including published protocols and trial registrations not including results); and (v) No psychiatric diagnosis $(n=3764$; including articles where participants did not have a clear psychiatric diagnosis).

Since limited details are provided in an abstract, a third phase was added in which the methods, but not the full texts, were superficially screened. Exclusion reasons for Phase 3 included: (i) Monitoring frequency $(n=$ 1674; including articles where monitoring was not done daily, weekly, bi-weekly, or monthly); (ii) Not studies on mood $(n=556$; including, for example, articles where alcohol intake or medication adherence was monitored, but not mood symptoms, or where mood was monitored as part of the larger study but findings did not include mood data); and (iii) Not studies on distant monitoring ( $n=126$; including articles where the intervention included face-to-face visits with clinicians (excluding treatment as usual) or research staff).

The fourth phase included a more thorough screening of the methodology section. During this phase, articles were excluded for the following reasons: (i) No feedback provided ( $n=75$; including articles where there was no feedback/support as per the criteria above); (ii) Education and therapy $(n=56$; where psychoeducation or psychotherapy formed part of the intervention); and (iii) Not main intervention $(n=6$; where monitoring was not the main intervention; for example where a new drug was being tested). These exclusion reasons were only added at a later phase since a much more thorough reading of the methodology section was needed.

Lastly, the full text of the remaining articles $(n=32)$ were screened to determine eligibility. Of the full text articles screened only 9 were included. Reasons for exclusion included: (i) Education and therapy $(n=5)$; (ii) Not monitoring $(n=4)$; (iii) Not mood $(n=6)$; (iv) Not distant $(n=2)$; (v) No feedback $(n=4)$; (vi) Not main $(n=$ $1)$; and (vii) No psychiatric diagnosis $(n=1)$.

\section{Quality assessment}

The first and second authors independently assessed the quality of the included studies using the Mixed Methods Appraisal Tool (MMAT) version 2018 [21, 32]. However, since two of the included studies $[5,28]$ were authored by the first author, a third independent researcher was asked to assess the quality of these two studies.

\section{Data collection}

The first author extracted the relevant information from the included studies, and the second author corroborated the information. The extracted data included study design, setting, sample, mood disorder, method of monitoring, any additional information deemed important, and study findings.

\section{Outcomes}

The two main outcomes for which the data were sought were (i) effectiveness, and (ii) feasibility of daily/weekly/ monthly remote/distant mood monitoring by distant supporters of participants with mood disorders. 


\section{Results}

\section{Eligible papers}

Nine articles [5, 28, 33-39] met the inclusion criteria for this systematic review. Mood monitoring studies were conducted in Chile [35], Denmark [33, 34], South Africa [5, 28], and the United States of America [36-39]. Details regarding study designs and monitoring procedures are presented in Table 1. Most studies used quantitative methods [5, 35-40], with only two studies [28, 34] including a qualitative component (semi-structured interviews). Details regarding outcome measures, effectiveness, adverse events, and completion rates are presented in Table 2. Information regarding Population, Intervention, Comparison, Outcome, and Time (PICOT) is embedded in both Table $1(\mathrm{P}, \mathrm{I}, \mathrm{C}, \mathrm{T})$ and Table $2(\mathrm{C}, \mathrm{O})$.

\section{Quality of the included papers}

Table 3 presents a summary of the MMAP quality assessment of the included articles. In general, the quality was deemed acceptable based on the different study designs. Methodological concerns related to sample representativeness [36], complete outcome data [38], control of confounding variables [39], a rationale for the use of a mixed method study design [28], and outcome assessors being blinded to the randomized controlled trial (RCT) intervention [37].

\section{Descriptive data: demographic information, mood disorder, and assessments}

As indicated in Table 1, the majority of participants in each study were female, ranging from $55.6 \%$ [34] to $89.2 \%$ [28], with the exception of the study by Ross and colleagues (2008) where females were the minority (6.7\%). Age of participants varied widely from as young as a mean age of 15.2 years [35] to above 66 years old [36]. Three studies [34, 39, 40] did not provide details on ethnicity. Two of the studies conducted in the USA included mainly white participants, ranging between 75.4\% [38] and 90\% [36]. Similarly, a Chilean study included mainly white $(83.2 \%)$ participants [36]. The remaining studies $[5,28,35,38]$ included diverse ethnic groups including African American, black, coloured (mixed race), Hispanic, and Mapuche participants.

Across the studies, included participants predominantly had depressive disorders [34-38]. Two studies included both depressive and bipolar disorders [5, 28], and two included only bipolar disorder participants $[39,40]$.

Outcome measures for depression included the Beck Depression Inventory (BDI) [35], the Hamilton Depression rating scale (HAM-D) [34, 39, 40], the Major Depression Inventory (MDI) [34], the Mini-International Neuropsychiatric Interview (MINI) [34, 37], the Patient Health Questionnaire (PHQ) [36-38], the Patient Global Impression Severity scale (PGI-S) [38], and the Quick
Inventory of Depressive Symptomatology (QIDS) [5, 28]. Outcome measures for mania included the Altman SelfRating Mania scale (ASRM) [5, 28] and the Young Mania Rating Scale (YMRS) [39, 40]. Only three studies specified the time at which distant mood monitoring had commenced in relation to the course of the disorder. For these studies, distant mood monitoring was initiated at 1 week post-discharge $[5,28]$ or following diagnosis [38]. The remaining studies indicated that outpatients were recruited [34-37, 39, 40].

\section{Feasibility}

For this systematic review, feasibility was based on compliance and completion rates, and on feedback provided by participants. For RCTs included in this review, control group completion rates ranged between $67.48 \%$ [38] and $87.18 \%$ [40]; while intervention group completion rates ranged between $72.37 \%$ [38] and $100 \%$ [35]. For the other included studies, completion rates ranged between $45.9 \%$ [5] and 76\% [34]. In the present review, only one study [28] reported on participants' subjective experiences of the acceptability of distant mood monitoring with support, and found high acceptability. However, Van der Watt, Roos, and colleagues (2018) also noted that some participants reported negative (10.8\%) and apprehensive (16.2\%) experiences of the baseline assessment prior to the commencement of mood monitoring. The negative experiences of baseline assessments, which included two trauma questionnaires, included feeling "... nervous ... like a rat in a trial" speaking to strangers (researchers) about personal experiences and feelings, and "... experience [ing] the reality again" of past experiences [28]. None of the included studies reported on adverse events directly linked to the mood monitoring.

\section{Effectiveness}

We defined effectiveness (or a lack thereof) in terms of an increase and/or decrease in depression and/or mania scores on a rating scale, as well as participants' selfreports of the helpfulness of the mood monitoring.

One study [36] did not specify whether there was an increase or decrease in depression scores. Two studies $[37,40]$ reported no significant decrease in depression scores, while three studies $[5,35,38]$ reported a significant decrease in depression scores following distant mood monitoring. Qualitatively, participants reported that distant mood monitoring was helpful [28]. However, it should be noted that this positive feedback was not limited to participants with major depressive disorder. Nonetheless, distant mood monitoring with support appears to be effective in decreasing depression symptoms.

Distant mood monitoring does not seem to be effective in significantly decreasing mania scores $[5,40]$ even 


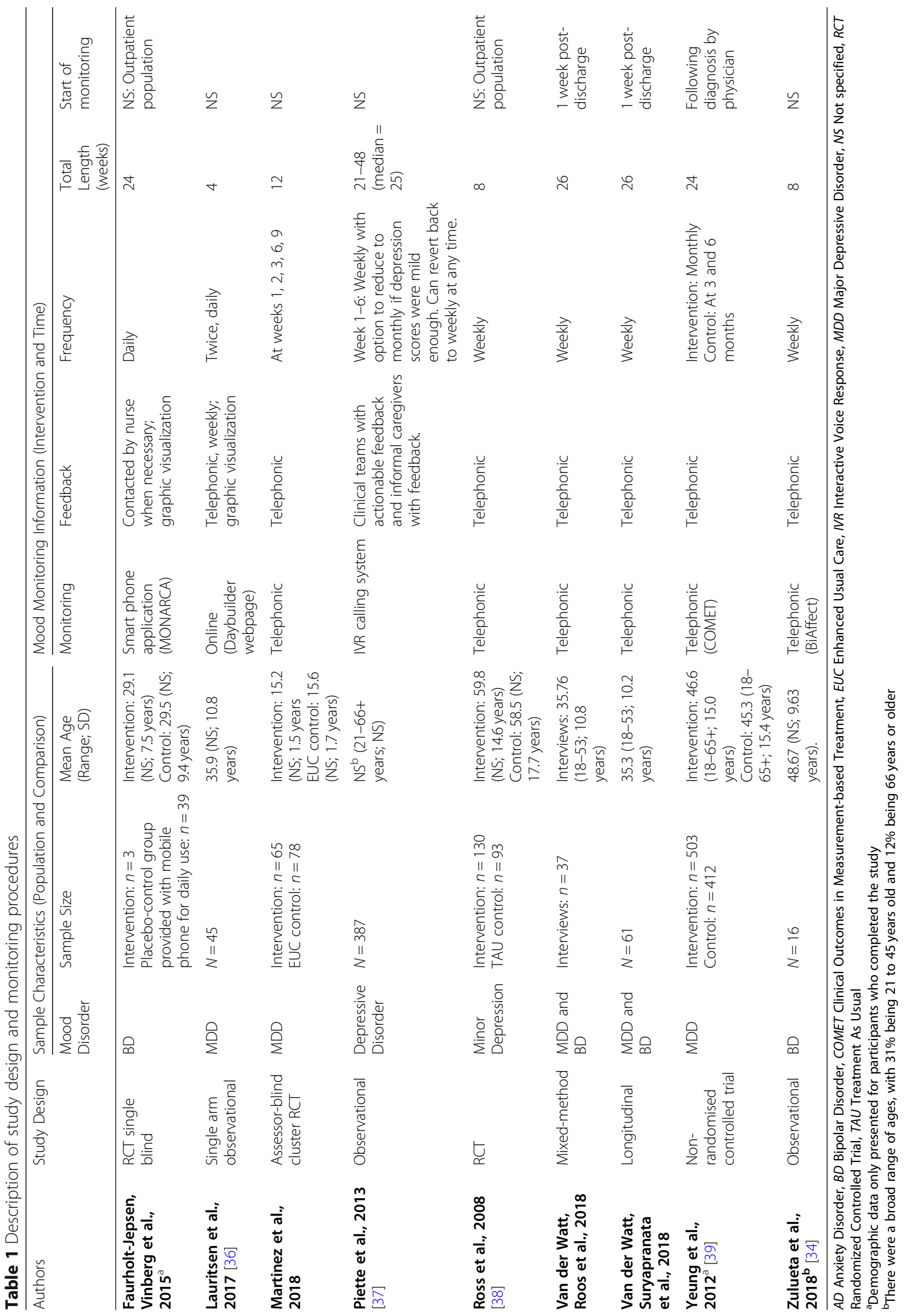




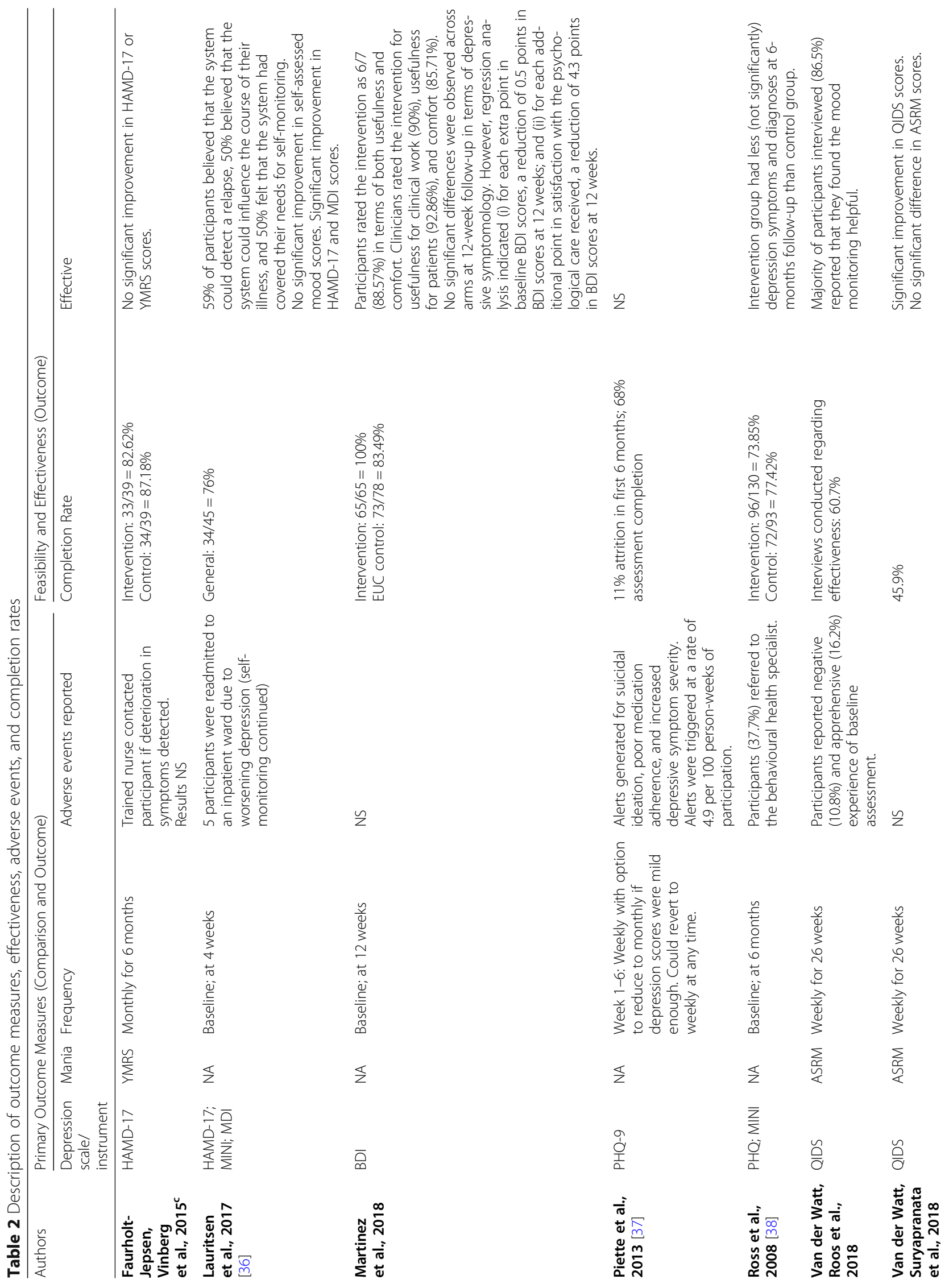




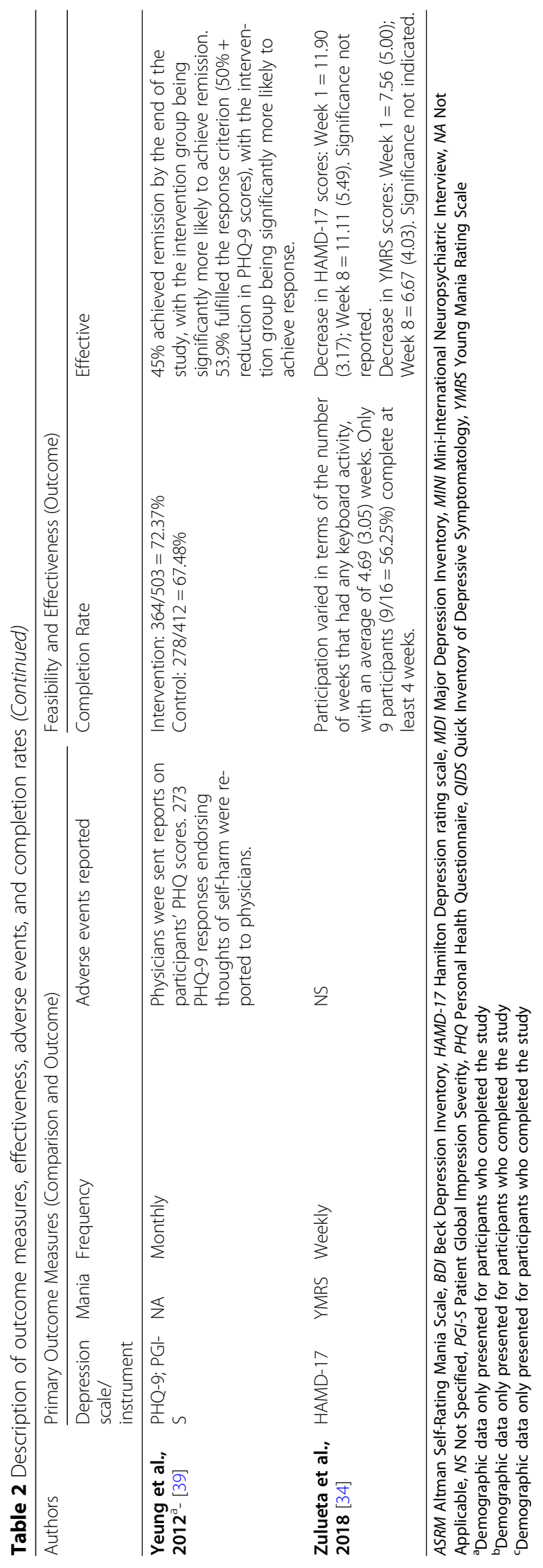



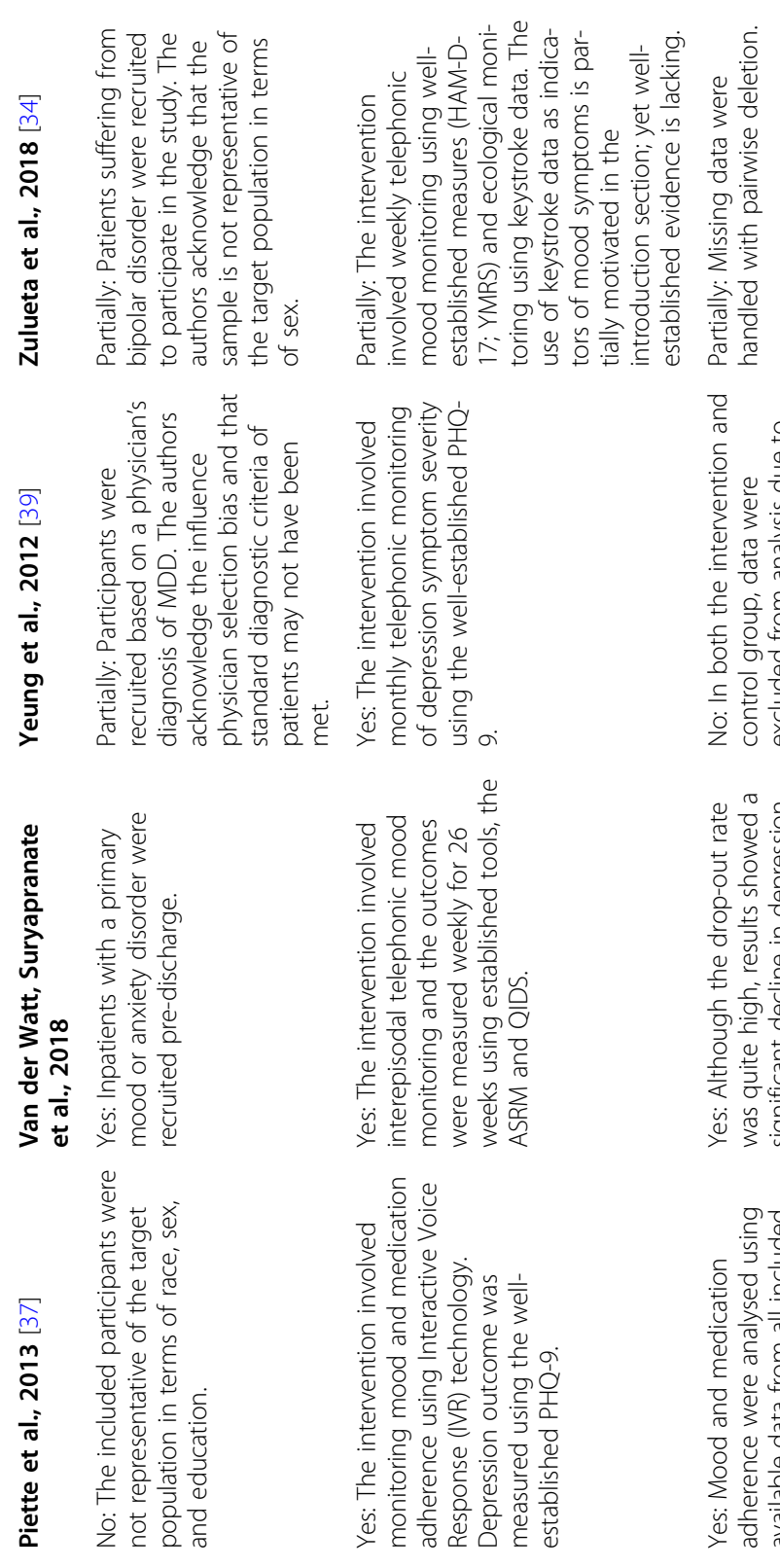

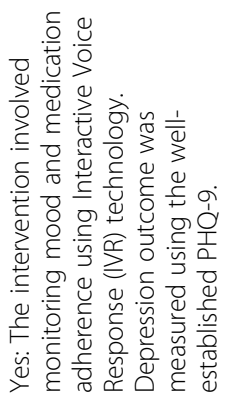

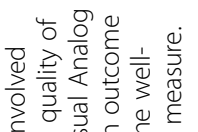

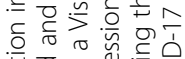

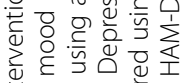

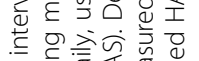

ष

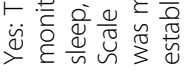

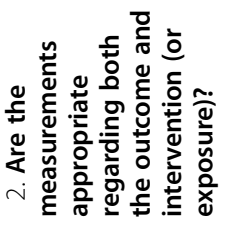

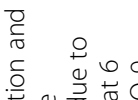

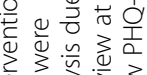

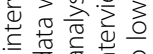

o

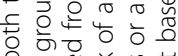

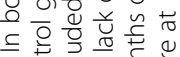

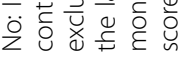

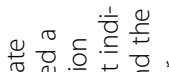

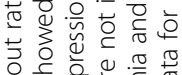

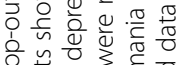

음

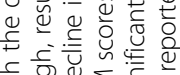

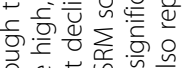

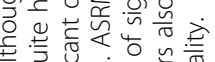

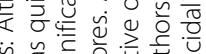

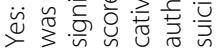
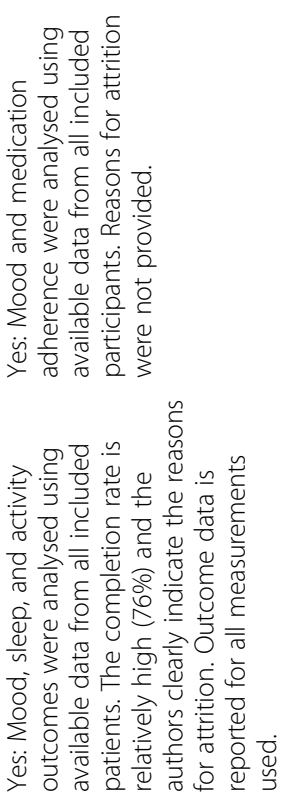

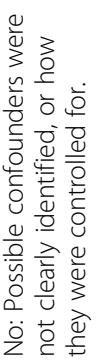

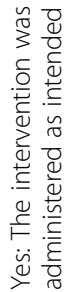

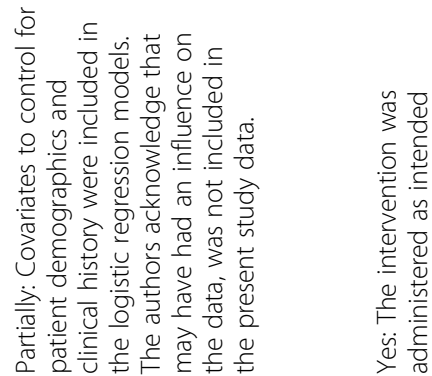

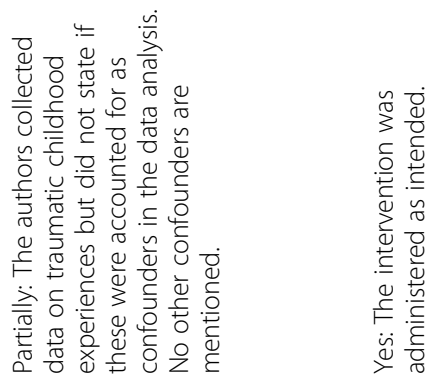

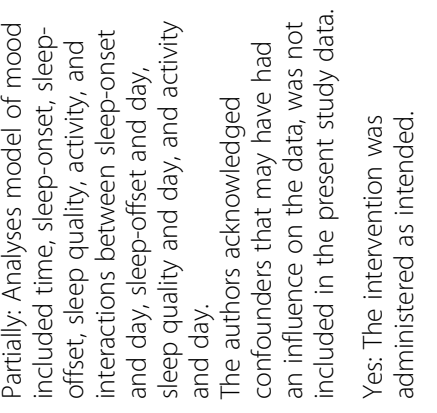
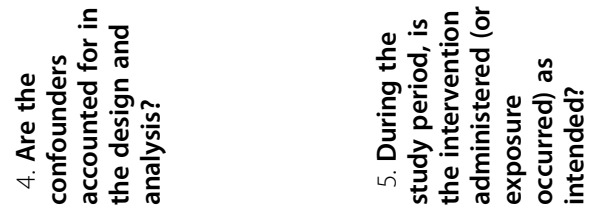


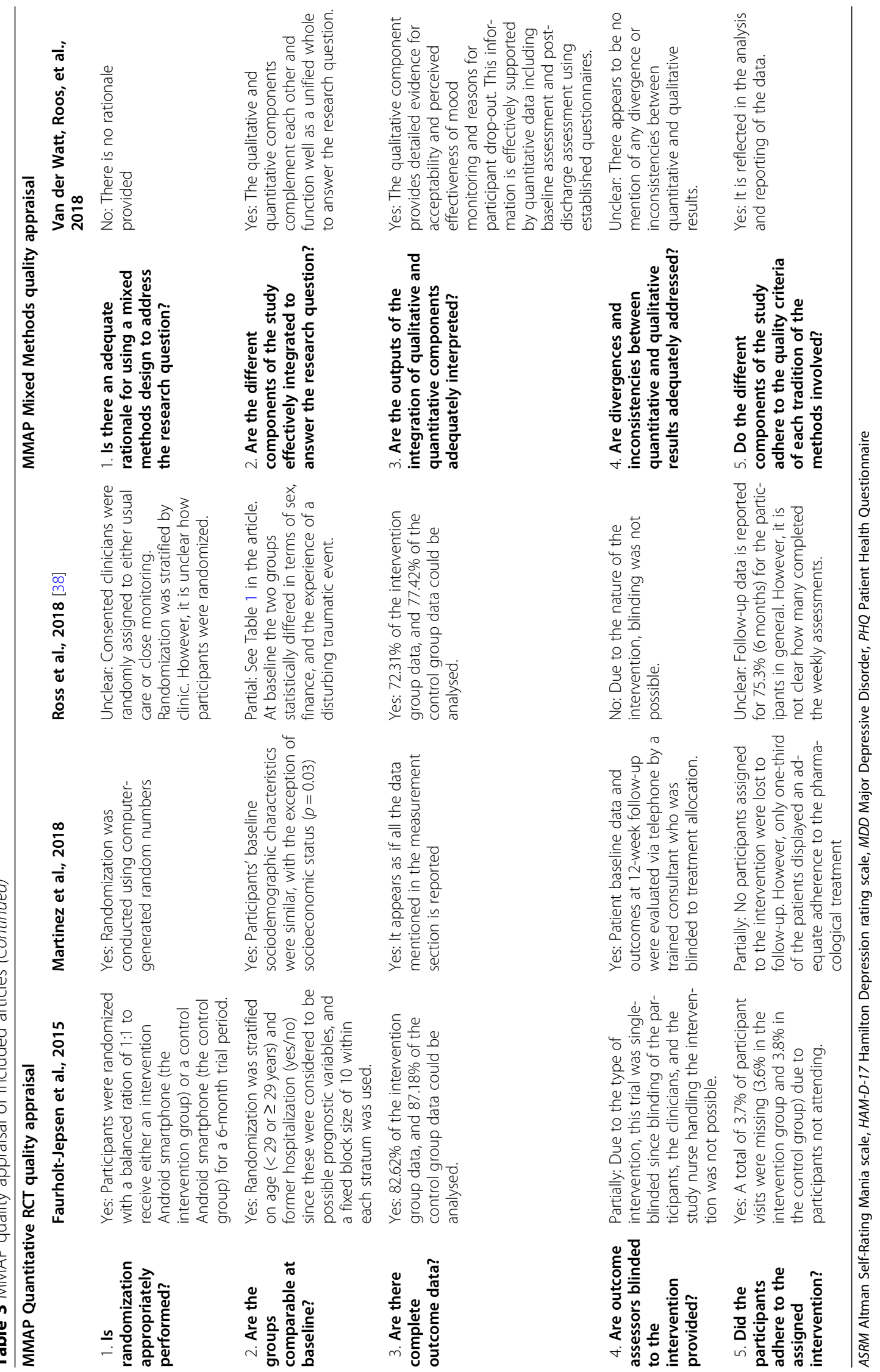


though the majority of participants $(86.5 \%)$ reported that the distant mood monitoring was helpful [28]. This was, however, not limited to participants with bipolar disorder. Further, Zulueta and colleagues (2018) reported a decrease in mania scores, yet they did not specify whether this decrease was statistically significant or not.

Throughout mood monitoring, adverse events may occur that are not necessarily because of the mood monitoring. In terms of such adverse events, four studies [5, $28,35,39$ ] did not report any adverse events or procedures to manage them. One study [40] indicated that trained nurses would contact participants should they detect a deterioration in symptoms, however, the authors did not indicate how often this occurred. Four studies specified adverse events that occurred during mood monitoring and/or procedures to manage them: readmission [34]; alerts generated for suicidal ideation, poor medication adherence, and increased depressive symptom severity [36]; referral to the behavioural health specialist following persistent or worsening depressive symptoms [37]; and thoughts of self-harm reported to physicians [38].

\section{Discussion}

Most of the studies included in the review were conducted in high income countries $(n=6)$. This highlights the need for more research to be conducted in developing countries. Due to the high prevalence of depressive and bipolar disorders in low- and middle-income countries (LMIC) (see for example [41-43]), combined with the lack of mental health providers (see for example [44-46]), task-shifting has become increasingly important (see for example $[47,48]$ ). Distant mood monitoring interventions with adjunctive support (which could be provided by trained lay counsellors and researchers) may help to alleviate the burden on mental health providers in LMIC.

Apart from the study by Ross and colleagues (2008), participants were mostly female. This likely reflects the higher prevalence rate of depressive and bipolar disorders in women $[49,50]$. The wide age range and ethnic diversity of participants suggests that distant mood monitoring, with feedback, has wide applicability.

Included studies mainly focused on depressive disorders $(n=5)$. This limits the generalisability of conclusions that can be made to patients with bipolar disorder. Further research is needed in this regard. Studies used a variety of instruments to determine depression (BDI, HAM-D, MINI, PHQ, PGI-S, and QIDS) and mania outcomes (ASRM, YMRS), which suggests that a number of measures may have applicability in distant mood monitoring. It should be noted that differences in outcome measures (i.e., use of different rating scales) across the studies may have impacted on responses [51] and outcomes $[52,53]$. Only three studies indicated that distant mood monitoring commenced 1 week postdischarge $(n=2)$ or upon diagnosis $(n=1)$. To arrive at more accurate conclusions about the effectiveness of mood monitoring with support, it is important that future publications include details on the baseline timepoint in relation to the illness course. A better understanding of the course of depressive and bipolar disorders, especially following discharge from hospital, may facilitate early intervention and the scheduling of appointments, particularly in low-resourced settings.

\section{Feasibility}

In general, distant mood monitoring with support was deemed feasible, with completion rates that are similar to those of distant self-mood monitoring interventions that did not include support [9]. Specifically, in their systematic review of distant self-mood monitoring, Faurholt-Jepsen and colleagues (2016) reported completion rates of between $42.1 \%$ [54] and 93.9\% [55, 56]. Further, distant mood monitoring with support was highly acceptable to participants, while some participants reported negative or apprehensive experiences at the baseline assessment. However, reporting bias should be considered as qualitative subjective reports were largely obtained from participants who completed the study, with only a few participants who dropped out of monitoring reporting their experiences [28]. None of the other included studies reported on adverse events or side effects of the mood monitoring itself. Further research is needed to determine any negative effects that mood monitoring may have.

\section{Effectiveness}

Distant mood monitoring with support was not effective in decreasing symptoms of mania. However, it does appear to be effective in decreasing depression symptoms. Thus, distant mood monitoring - as a task-shifting, relatively low-cost intervention - may be especially relevant in LMIC to assist in the treatment of depression. Considering the lack of information in this regard, the optimal time point at which to commence distant mood monitoring has yet to be determined.

Further, distant mood monitoring with support appeared to be effective in the timeous reporting of adverse events, such as symptom deterioration [34, 36, 40], suicidal ideation, poor medication adherence [36], and thoughts of self-harm [38]. This allowed for prompt intervention including readmission [34] and referral to behavioural health specialists [37]. These findings support previous research that distant mood monitoring may assist in improving treatment adherence [11]. Specifically, the involvement of distant supporters may 
facilitate the prevention and management of adverse outcomes [14]. Since treatment non-adherence is a major obstacle in the effective treatment of depressive and bipolar disorders $[57,58]$ the value of interventions that improve treatment adherence, such as distant mood monitoring, cannot be overstated. Furthermore, research has indicated that the level of motivation and engagement by a therapist [59] or supporter is correlated with treatment adherence. This strengthens the case for distant mood monitoring with support rather than mood monitoring without support.

\section{Limitations and recommendations}

The present findings are based on a small $(n=9)$ number of published articles. Further, only four studies included control groups which play an important role in results interpretation. Studies with control groups, are recommended. The heterogeneity of study design and loose definitions of feasibility and effectiveness are additional limitations. Changes in depression and mania scores may not necessarily correlate with improvement in quality of life or functioning. Also, the databases that we searched did not include PsychInfo as our university does not have a license for this database. Strengths of this systematic review include two independent systematic searches as well as the use of a second, blinded, author screening process.

Distant mood monitoring with distant supporter feedback is an appealing intervention, particularly in low resource settings and during times when face-to-face contact is restricted, such as the COVID-19 crisis. Further research is need to better understand the role of distant mood monitoring with distant support and to confirm their feasibility and effectiveness in routine clinical care across different settings. This includes a better understanding of the timing of the intervention in terms of phase of illness, the potential harmful effects of regular mood monitoring with support, and barriers to the use and implementation of such monitoring systems.

More rigorous mood monitoring studies are needed to draw more definitive conclusions. These studies should provide more detail on (i) mechanisms of monitoring (for example what the feedback entails), (ii) mood trajectories (e.g. at different time-points instead of only at baseline and endpoint), (iii) adverse events related/unrelated to the mood monitoring itself, (iv) the experiences and perceptions of the participants during mood monitoring, and (v) the quality of life impact of treatment.

\section{Conclusion}

This systematic review focused on the effectiveness and feasibility of daily/weekly/monthly remote mood monitoring in participants with any mood disorder by distant supporters or where regular feedback was provided by distant supporters in cases where mood states were selfassessed. Nine studies were found to be eligible for inclusion. Given the differences in sample characteristics, methodology, and outcome measures it is difficult to draw comparisons and definitive conclusions across the studies. However, we tentatively conclude that distant mood monitoring with support may be a useful and acceptable intervention for a diverse population in terms of age and ethnicity. Feasibility, as measured through completion rates and subjective feedback, is deemed acceptable. Further, distant mood monitoring with support may be effective in improving depression symptoms, increase treatment adherence, and facilitate the prevention and management of adverse outcomes. As a task-shifting intervention, distant mood monitoring may help to alleviate the burden on mental health providers in developing countries. These interventions also have appeal in a time when face-to-face contact is restricted and there is an expected increase in burden on the mental health system.

\section{Abbreviations \\ AD: Anxiety disorder; BD: Bipolar disorder; ASRM: Altman self-rating mania scale; BDI: Beck depression inventory; COMET: Clinical outcomes in measurement-based treatment; EUC: Enhanced usual care; HAMD- 17: Hamilton depression rating scale; IT: Information technology; IVR: Interactive voice response; MDD: Major depressive disorder; MDI: Major depression inventory; MINI: Mini-International Neuropsychiatric Interview; NA: Not applicable; NS: Not specified; PGI-S: Patient global impression severity; PHQ-9: Personal health questionnaire; QIDS: Quick inventory of depressive symptomatology; RCT: Randomized controlled trial; \\ TAU: Treatment as usual; YMRS: Young Mania Rating Scale}

\section{Acknowledgments}

We would like to thank the library staff for their kind assistance.

\section{Authors' contributions}

AvdW conducted the literature search, the screening process, the quality check, data extraction, and writing of the article. WO conducted an independent literature search, and served as second review during the screening process, quality check and data extraction. WO also contributed to writing the article. $\mathrm{KL}$ contributed to writing the article. SS contributed to writing the article. All authors have read and approved the manuscript.

\section{Funding}

This review is supported by the South African Research Chair in PTSD hosted by the Stellenbosch University, funded by the DST and administered by the NRF. The funding body was not directly involved in the design of the study; the data collection, analysis, and interpretation; or the writing of the manuscript.

\section{Availability of data and materials \\ Only summarized data from published articles are presented in this manuscript. The published articles are available from the respective authors and journals.}

\section{Ethics approval and consent to participate}

No ethics approval was required for this systematic review, nor consent to participate.

\section{Consent for publication}

No individual-level data are included in the present study. As such, consent for publication is not needed. 


\section{Competing interests}

We have no financial or non-financial competing interests to declare.

\section{Author details}

'Department of Psychiatry, Stellenbosch University, Tygerberg, South Africa. ${ }^{2}$ Health Systems Research Unit, South African Medical Research Council, Cape Town, South Africa.

\section{Received: 7 May 2020 Accepted: 8 July 2020}

Published online: 22 July 2020

\section{References}

1. Proudfoot J, Whitton AE, Parker G, Manicavasagar V, Nicholas J, Smith M. Evidence of weekly cyclicity in mood and functional impairment in those with a bipolar disorder. Psychiatry Res. 2014;218(3):290-4. https://doi.org/10. 1016/j.psychres.2014.04.047.

2. Sadock BJ, Sadock VA. Kaplan \& Sadock's synopsis of psychiatry: Behavioural sciences/clinical psychiatry. 10th ed. Philidelphia: Wolters Kluwer; 2007

3. Samamé C, Martino DJ, Strejilevich SA. Longitudinal course of cognitive deficits in bipolar disorder: A meta-analytic study. J Affect Disord. 2014;164: 130-8. https://doi.org/10.1016/j.jad.2014.04.028.

4. Glasziou P, Irwig L, Mant D. Monitoring in chronic disease: A rational approach. Br Med J. 2005;330(7492):644-8. https://doi.org/10.1136/bmj.330 7492.644 .

5. van der Watt ASJ, Suryapranata APSP, Seedat S. Prospective interepisoda mood monitoring in patients with affective disorders: A feasibility study Neuropsychiatr Dis Treat. 2018;14:517-24. https://doi.org/10.2147/NDT. S152620.

6. Ure J, et al. Piloting tele-monitoring in COPD: a mixed methods exploration of issues in design and implementation. Prim Care Respir J. 2011;21(1):5764. https://doi.org/10.4104/pcri.2011.00065.

7. Bopp JM, Miklowitz DJ, Goodwin GM, Stevens W, Rendell JM, Geddes JR. The longitudinal course of bipolar disorder as revealed through weekly text messaging: a feasibility study. Bipolar Disord. 2010;12(3):327-34. https://doi. org/10.1111/j.1399-5618.2010.00807.x.

8. Miklowitz DJ, et al. Facilitated Integrated Mood Management for adults with bipolar disorder. Bipolar Disord. 2012;14(2):185-97. https://doi.org/10.1111/j. 1399-5618.2012.00998.x.

9. Faurholt-Jepsen M, Munkholm K, Frost M, Bardram JE, Kessing LV. Electronic self-monitoring of mood using IT platforms in adult patients with bipolar disorder: A systematic review of the validity and evidence. BMC Psychiatry. 2016;16(1):7. https://doi.org/10.1186/s12888-016-0713-0.

10. Depp CA, et al. Augmenting psychoeducation with a mobile intervention for bipolar disorder: A randomized controlled trial. J Affect Disord. 2015;174: 23-30. https://doi.org/10.1016/j.jad.2014.10.053.

11. Wenze SJ, Armey MF, Miller IW. Feasibility and Acceptability of a Mobile Intervention to Improve Treatment Adherence in Bipolar Disorder. Behav Modif. 2014;38(4):497-515. https://doi.org/10.1177/0145445513518421.

12. Newman MG, Szkodny LE, Llera SJ, Przeworski A. A review of technologyassisted self-help and minimal contact therapies for anxiety and depression: Is human contact necessary for therapeutic efficacy? Clin Psychol Rev. 2011; 31(1):89-103. https://doi.org/10.1016/j.cpr.2010.09.008.

13. Todd NJ, Jones SH, Hart A, Lobban FA. A web-based self-management intervention for Bipolar Disorder 'Living with Bipolar': A feasibility randomised controlled trial. J Affect Disord. 2014;169:21-9. https://doi.org/ 10.1016/j.jad.2014.07.027

14. Newham JJ, Martin CR. Measuring fluctuations in maternal well-being and mood across pregnancy. J Reprod Infant Psychol. 2013;31(5):531-40. https:// doi.org/10.1080/02646838.2013.834040.

15. Kvale S. InterViews: An introduction to qualitative research interviewing. Michigan: Sage Publications; 1996.

16. Hidalgo-Mazzei D, Mateu A, Reinares M, Matic A, Vieta E, Colom F. Internetbased psychological interventions for bipolar disorder: Review of the present and insights into the future. J Affect Disord. 2015;188:1-13. https:// doi.org/10.1016/j.jad.2015.08.005.

17. World Health Organization, "World Health Organization guideline: Recommendations on digital interventions for health system strengthening." 2019.

18. W. A. Odendaal et al., "Health workers' perceptions and experiences of using mHealth technologies to deliver primary healthcare services: a qualitative evidence synthesis," Cochrane Database Syst Rev, 2020, doi: https://doi.org/ 10.1002/14651858.CD011942.pub2.

19. Marcolino MS, Oliveira JAQ, D'Agostino M, Ribeiro AL, Alkmim MBM, NovilloOrtiz D. The Impact of mHealth Interventions: Systematic Review of Systematic Reviews. JMIR mHealth uHealth. 2018;6(1):e23. https://doi.org/10. 2196/mhealth.8873.

20. Mbuagbaw L, Medley N, Darzi AJ, Richardson M, Habiba Garga K, OngoloZogo P. Health system and community level interventions for improving antenatal care coverage and health outcomes: Cochrane Database Syst Rev; 2015. https://doi.org/10.1002/14651858.CD010994.pub2.

21. Hong QN, Gonzalez-Reyes A, Pluye P. Improving the usefulness of a tool for appraising the quality of qualitative, quantitative and mixed methods studies, the Mixed Methods Appraisal Tool (MMAT). J Eval Clin Pract. 2018; 24(3):459-67. https://doi.org/10.1111/jep.12884.

22. Greenhalgh T. Effectiveness and efficiency of search methods in systematic reviews of complex evidence: audit of primary sources. BMJ. 2005;331(7524): 1064-5. https://doi.org/10.1136/bmj.38636.593461.68.

23. American Psychiatric Association. Diagnostic and Statistical Manual of Mental Disorders. 4th ed. Washington: American Psychiatric Association; 2000.

24. American Psychiatric Association. Diagnostic and statistical manual of mental disorders. 5th ed. Washington, DC: Author; 2013.

25. World Health Organization, "International statistical classification of diseases and related health problems.," 2018. [Online]. Available: https://icd.who.int/ browse11/l-m/en.

26. Billsborough J, et al. Listen, empower us and take action now!': reflexivecollaborative exploration of support needs in bipolar disorder when 'going up' and 'going down. J Ment Health. 2014;23(1):9-14. https://doi.org/10. 3109/09638237.2013.815331.

27. Lowes L, Paul G. Participants' experiences of being interviewed about an emotive topic. J Adv Nurs. 2006;55(5):587-95. https://doi.org/10.1111/j.13652648.2006.03950.x

28. van der Watt ASJ, Roos T, Beyer C, Seedat S. Participants ' perspectives of weekly telephonic mood monitoring in South Africa : a feasibility study. Pilot Feasibility Stud. 2018;56(4):1-11. https://doi.org/10.1186/s40814-018-0245-0.

29. Patel MX, Doku V, Tennakoon L. Challenges in recruitment of research participants. Adv Psychiatr Treat. 2003;9(3):229-38. https://doi.org/10.1192/ apt.9.3.229.

30. Tutty S, Ludman EJ, Simon G. Feasibility and acceptability of a telephone psychotherapy program for depressed adults treated in primary care. Gen Hosp Psychiatry. 2005;27(6):400-10. https://doi.org/10.1016/j.genhosppsych. 2005.06.009.

31. Ouzzani M, Hammady H, Fedorowicz Z, Elmagarmid A. Rayyan - a web and mobile app for systematic reviews. Syst Rev. 2016:5(1):210. https://doi.org/ 10.1186/s13643-016-0384-4.

32. Pace $\mathrm{R}$, et al. Testing the reliability and efficiency of the pilot Mixed Methods Appraisal Tool (MMAT) for systematic mixed studies review. Int J Nurs Stud. 2012;49(1):47-53. https://doi.org/10.1016/j.jinurstu.2011.07.002.

33. Faurholt-Jepsen M, Frost M, Vinberg M, Christensen EM, Bardram JE, Kessing LV. Smartphone data as objective measures of bipolar disorder symptoms. Psychiatry Res. 2014;217(1-2):124-7. https://doi.org/10.1016/j. psychres.2014.03.009.

34. Lauritsen L, et al. Usability, acceptability, and adherence to an electronic self-monitoring system in patients with major depression discharged from inpatient wards. J Med Internet Res. 2017;19(4):1-12. https://doi.org/10.2196/ jmir.6673.

35. Martínez $\mathrm{V}$, et al. Remote collaborative depression care program for adolescents in araucanía region, Chile: Randomized controlled trial. J Med Internet Res. 2018;20(1). https://doi.org/10.2196/jmir.8021.

36. Piette JD, et al. Depression self-management assistance using automated telephonic assessments and social support. Am J Manag Care. 2013;19(11):892-900.

37. Ross JT, Tenhave T, Eakin AC, Difilippo S, Oslin DW. A randomized controlled trial of a close monitoring program for minor depression and distress. J Gen Intern Med. 2008;23(9):1379-85. https://doi.org/10.1007/s11606-008-0663-4.

38. Yeung AS, et al. Clinical Outcomes in Measurement-based Treatment (COMET): A trial of depression monitoring and feedback to primary care physicians. Depress. Anxiety. 2012;29(10):865-73. https://doi.org/10.1002/da.21983.

39. Zulueta J, et al. Predicting mood disturbance severity with mobile phone keystroke metadata: A biaffect digital phenotyping study. J Med Internet Res. 2018;20(7):1-10. https://doi.org/10.2196/jmir.9775. 
40. Faurholt-Jepsen M, Vinberg M, Frost M, Christensen EM, Bardram JE, Kessing LV. Smartphone data as an electronic biomarker of illness activity in bipolar disorder. Bipolar Disord. 2015;17(7):715-28. https://doi.org/10.1111/bdi. 12332.

41. Patel V, Kleinman A. Poverty and common mental disorders in developing countries. Bull World Health Organ. 2003;81(8):609-15.

42. Ribeiro WS, et al. Income inequality and mental illness-related morbidity and resilience: a systematic review and meta-analysis. Lancet Psychiatry. 2017;4(7):554-62. https://doi.org/10.1016/\$2215-0366(17)30159-1.

43. World Health Organization, "Depression and other common mental disorders: Global health estimates," 2017.

44. Rathod S, et al. Mental Health Service Provision in Low- and Middle-Income Countries. Heal Serv Insights. 2017;10:117863291769435. https://doi.org/10. $1177 / 1178632917694350$.

45. Wang PS, et al. Use of mental health services for anxiety, mood, and substance disorders in 17 countries in the WHO world mental health surveys. Lancet (London). 2007;370(9590):841-50. https://doi.org/10.1016/ S0140-6736(07)61414-7.

46. 1, "Mental Health Atlas-2011," 2011.

47. Deimling Johns L, Power J, MacLachlan M. Community-based mental health intervention skills: Task shifting in low- and middle-income settings. Int Perspect Psychol Res Pract Consult. 2018;7(4):205-30. https://doi.org/10. 1037/ipp0000097.

48. Javadi D, Feldhaus I, Mancuso A, Ghaffar A. Applying systems thinking to task shifting for mental health using lay providers: a review of the evidence. Glob Ment Heal. 2017;4:e14. https://doi.org/10.1017/gmh.2017.15.

49. American Psychiatric Association. Diagnostic and statistical manual of mental disorders. 4th ed. Arlington: American Psychiatric Association; 2013.

50. Ferrari AJ, et al. The prevalence and burden of bipolar disorder: findings from the Global Burden of Disease Study 2013. Bipolar Disord. 2016;18(5): 440-50. https://doi.org/10.1111/bdi.12423.

51. Weijters $B$, Cabooter $E$, Schillewaert $N$. The effect of rating scale format on response styles: The number of response categories and response category labels. Int J Res Mark. 2010;27(3):236-47. https://doi.org/10.1016/j.jiresmar. 2010.02.004

52. Faravelli C, Albanesi G, Poli E. Assessment of depression: A comparison of rating scales. J Affect Disord. 1986;11(3):245-53. https://doi.org/10.1016/ 0165-0327(86)90076-5.

53. Svanborg P, Åsberg M. A comparison between the Beck Depression Inventory (BDI) and the self-rating version of the Montgomery Asberg Depression Rating Scale (MADRS). J Affect Disord. 2001;64(2-3):203-16. https://doi.org/10.1016/S0165-0327(00)00242-1.

54. Depp CA, et al. Mobile interventions for severe mental illness: design and preliminary data from three approaches. J Nerv Ment Dis. 2010;198(10):71521. https://doi.org/10.1097/NMD.0b013e3181f49ea3.

55. Bauer M, Grof P, Gyulai L, Rasgon N, Glenn T, Whybrow PC. Using technology to improve longitudinal studies: self-reporting with ChronoRecord in bipolar disorder. Bipolar Disord. 2004;6(1):67-74.

56. Whybrow PC, Grof P, Gyulai L, Rasgon N, Glenn T, Bauer M. The electronic assessment of the longitudinal course of bipolar disorder: the ChronoRecord software. Pharmacopsychiatry. 2003;36(Suppl 3):S244-9. https://doi.org/10.1055/s-2003-45137.

57. Pompili $M$, et al. Improving adherence in mood disorders: the struggle against relapse, recurrence and suicide risk. Expert Rev Neurother. 2009;9(7): 985-1004. https://doi.org/10.1586/ern.09.62.

58. Gaudiano BA, Weinstock LM, Miller IW. Improving treatment adherence in bipolar disorder: a review of current psychosocial treatment efficacy and recommendations for future treatment development. Behav Modif. 2008; 32(3):267-301. https://doi.org/10.1177/0145445507309023.

59. Roos J, Werbart A. Therapist and relationship factors influencing dropout from individual psychotherapy: A literature review. Psychother Res. 2013; 23(4):394-418. https://doi.org/10.1080/10503307.2013.775528.

\section{Publisher's Note}

Springer Nature remains neutral with regard to jurisdictional claims in published maps and institutional affiliations.

\section{Ready to submit your research? Choose BMC and benefit from}

- fast, convenient online submission

- thorough peer review by experienced researchers in your field

- rapid publication on acceptance

- support for research data, including large and complex data types

- gold Open Access which fosters wider collaboration and increased citations

- maximum visibility for your research: over $100 \mathrm{M}$ website views per year

At BMC, research is always in progress.

Learn more biomedcentral.com/submissions 